\title{
BATAILLE POR Y MÁS ALLÁ DE SÍ MISMO: APUNTES PARA UNA LECTURA DE GRUPO CONTRA-ATTAQUE
}

\author{
Tomás Ramos Mejía ${ }^{1}$ \\ Universidad de Buenos Aires, IIGG, Argentina
}

http://dx.doi.org/10.5209/NOMA.55418

\begin{abstract}
Resumen: El presente trabajo se propone dos objetivos:realizar un breve repaso por algunas de las lecturas que se hicieran del grupoContre-Attaque; luego, a partir de trabajos realizados por Jean-Luc Nancy en torno a la noción de comunidad, llevar adelante un análisis de las ideas existenes en determinados textos publicados por el grupo para, finalmente, desarrollar una reflexión sobre la exigencia comunitaria presente en la obra de Georges Bataille.
\end{abstract}

Palabras clave: violencia, comunidad, política, fascismo

\section{Bataille for and beyond himself: notes for a review about Contre-Attaque group}

Abstract: This paper has two goals: in the first place, to briefly review some of the writings regarding Contre-Attaque; then, based on Jean-Luc Nancy's work regarding the idea of community, to analyse the notions of some of the writing issued by the group. Finally, we will draw a conclusion on the communal demand found in the works of Georges Bataille.

Key words: violence, community, politics, fascism.

\section{Introducción:}

En 1934 se disuelve el Cercle communite democratique, grupo de reflexión heteróclito en el que Georges Bataille participó y en cuya revista, Le Critique sociale, habrá publicado tres de sus artículos más importantes: La notion de dépense, LeProbleme de l'etaty Le structure psychologique du fascisme. Será en 1935 que Bataille volverá a ser parte de un grupo, en este caso alentando él mismo su formación y nopudiendo caracterizarse exactamente como grupo de reflexión. Michel Suyra,biógrafo de Bataille y autor de Georges Bataille, la muerte obradefine al grupo ContreAttaquecomo "una de las últimas y más significativas reacciones de ultraizquierda intelectual francesa antes de la Segunda Guerra mundial"(Suyra, 2014).Su surgimiento estuvo motivado, según las palabras del propio Bataille, por la intención de "...contribuir a un desarrollo bursco de la ofensiva revolucionaria." (Bataille, 1970,).Reconciliándose con su viejo enemigo André Bretón, y aliándose a él, acuerda una reunión con el surrealistaen

1 Tomás Ramos Mejía es Licenciado en Sociología por la Universidad de Buenos Aires (UBA) y maestrando en Sociología de la Sultura y Análisis Cultural por el Instituo de Altos Estudios Sociales, (IDAES) de la Universidad de San Martín (UNSAM). 
el Caféde la Régence en septiembre de 1935; el agrupamiento emite su primer manifiesto el 7 de Octubre,comienzan sus actividades en Noviembre y antes de cumplir el año, en Mayo de 1936,ya se habrá separado.

Contre-Attaque estuvo conformado sobre todo por surrealistas, batailleanos $^{2}$ y personas no adheridas a ningún colectivo. No resulta importante aquí nombrar sus integrantes - trabajo ya realizado por otros, sino que basta con mencionar que, tal como Surya y Marmmande(2003)hacen saber, las ideas Contre-Attaque eran las ideas de Bataille. Suyra, basándose en el realto de Henry Dubief, historiador y partícipe del grupo, no vacila al afirmar que "Contre-Attaque pertenció a Bataille, que las ideas defendidas y el estilo adoptado fueron los suyos"(Suyra, 2014).En este sentido, Marmande exige pensar el "lenguaje puesto en acción como una condensación de la problemática que se elabora en los escritos de Bataille desde hace mucho tiempo y como el resultado muy ineficaz (pero ruidoso) de una necesidad histórica"(Marmmande, 2009). Invita aquí a esbozar una reflexion sobrela "exigencia comunitaria" presente en la obra de Bataille a partir de La comunidad operante de Jean-Luc-Nancy.

Centrándonos sobre todo en este último punto, en adelante se realizará un breve repaso por algunas de las lecturas que se hicieran del grupo, para luego intentar encontrar en ciertas reflexiones de Jean-Luc Nancy en torno a la problemática de la comunidad herramientas conceptuales que permitan desarrollar un análisis que, aunque provisorio e incompleto, resulte novedoso e intente darle un lugar más preciso a Contre-Attaque dentro del pensamiento político de Georges Bataille.

\section{Interpretaciones:}

A. El llamado a la acción violenta y el problema del límite.

En 1976 se publica el acta de un coloquio dedicado a Georges Bataille en el que se presentará, entre otros, Jean-Luis Houdebine. Allí él plantearía algunas reflexiones respecto de la relación y las criticas de Georges Bataille al surrealismo, y explicaría la emergencia del grupo Contre-attaque como la alianza resulante de las específicas circunstancias históricas, esto es, la amenaza fascista en Francia: "En 1935-1936 se produce la frustrada tentativa de un reagrupamiento de intelectuales revolucionarios en torno a Bataille y Breton, cuya efímera reunión (...) es en sí misma función de un contexto político inmediatamente determinante (amenazas fascistas en francia, tras el triunfo del nazismo." (Houdebine, 1976).

2Suyra aclara que con ese término denomina a aquellos que, tras la disolución del Cercle communiste democratique, se aliaron a él. 
Como puede observarse, si bien no es el objeto de reflexión del texto, Contre-Attaque aparece aqui reducido a una alianza, resultado de una de decisión estratégica-política, que las diferencias profundas entre Bataille y Bretón no permitirían perdurar.De allí resulta que el autor asuma entonces que dicha alianza puede ser caracterizada simplemente como antifascista, una constante en los estudios que no analizan con detalle los textos publicados con el grupo. En la misma línea,Sergio Alonso Mislata, en Georges Bataille y la ausencia del mito, lo define como "un grupo de intelectuales anti-fascistas "(Alonso Mislata, 2014) con grandes pero poco definidos objetivos. Marca, sin embargo, dos características importantes y relacionadas entre sí: por una parte, una urgencia de acción conjunta; por otro, la inexistencia de reflexiones extensas como las que se podrían encontrar en La Critique sociale.

No puede negarse que haya habido un contexto político inemdiatamente determinantedetrás de la alianza entre Bataille y Bretón, como tampoco puede rechazarse que hayan existido fuertes tensiones entre ellos detrás de la disolución del grupo, peroContreAttaque no puede reducirse a ello, sino que parece tener, a pesar de su carácter efímero, un lugar determinado en la historia del Georges Bataille político.

Michel Suyra agrega otras caracteríticas que compartiría con otros grupos de izquierda: antinacionalismo, anticapitalismo, reformismo (solo comandada por los obreros en el poder), antidemocratismo y antiparlamentarismo. Pero presenta, además, una característica singular que se desprende de la lectura que Bataille realizara sobre el fascismo, esto es, de aquello que para Bataille hizo al fascsimo superior: la capacidad de destituir la democracia por medio de la prosvisión de mitos colectivos y fe. De ahí que no haya salida posible por medio de los mencanimos democrático-parlamentarios; de ahí, entonces, que Contre-Attaque pretendiera servirse de las "armas" que fueron creadas por el fascismo para dar fuerza a la verdadera revolución, en concordancia con el interés universal de los hombres.La revolución, nos hace saber Suyra, será una revolución de las costumbres que, desprendiéndose de la moral impuesta por los padres, permitirá la libre expresión de las pasiones y el acceso a goces hasta ese momento constreñidos por la educación capitalista y burguesa.

El autor, a diferencia de las anteriores lecturas, no desconoce la presencia de un elemento que presenta una gran trascendencia para este trabajo. Hablamos del llamado a la violencia:"Pero para conseguir llegar a ello -la liberacion del hombre- se precisará una revolución violenta. Contre-Attaque rebosa de llamamientos a la violencia (...) violencia y dictadura del pueblo" (Suyra, 2014)

La tensiones entre Bretón y Bataille suscitaron el alejamiento de los surrealistas, quienes acusaron a Bataille de "sobrefascista". Más allá de 
los acontecimientos específicos que finalizaron la corta alianza entre ellos ${ }^{3}$, es cierto que Bataille, pero tambiénBretón -remarca Suyra-, autorizó una octavilla, cuyo autor fue Jean Dautry, en la que puede leerse lo siguiente: "Preferimos en todo caso la brutalidad antidiplomática de Hitler, más pacífica de hecho que la exaltación babosa de dipolmáticos y políticos" (Bataille, 1977).Si bien es cierto tambien que Bataille no parece capaz de llevar tan lejos su rechazo por la burguesía parlamentaria, para Suyra, "lo que esperaba Bataille era que una sublevación humana acabara arrollando con todo lo que suponía un límite: en una palabra, que se volviera soberana (...)En esto al menos, en esto en última instancia, Bataille no era un hombre de izquierdas, al menos no como se lo entiende generalmente." (Suyra, 2914)

Francis Marmande percibe algo similar. En Georges Bataille, político, desarrolla un estudio acerca del pensamiento político de Bataille y define a Contre-Attaque como un movimiento habitado por una demanda de acción: "...partidario de la acción y llevado por una especie de lirismo de la demanda, del grito, de la locura y de la calle."(Marmande, 2009). El autor hace hincapié en el llamado a la acción que, como nos adelantó suyra, no es otra que una acción violenta. Basándose también en el relato de Dubief y señalando el "rol teórico" de Bataille, su dominio del "análisis político", coincide con Suyra cuando afirma que Contre-Attaque aparece como un llamado a la acción que se sobrepone a su pesimismo.

Ve al mismo tiempo una radicalización de las reflexiones que Bataille llevó a cabo sobre la teoría marxista y de ciertas ideas que en textos comole Probleme de l'etatole structure psychologique du fascismeintentaban solucionar problemas en la teoría marxista. No analizaremos tal afirmaición porque excede el objetivo del presente trabajo, pero sí retenemos, por el momento, que Marmande ve en el movimiento la puesta en acción de convicciones presentadas en dichos textos: "oposición al Estado, a toda forma de organización, que aunque fuera social en lugar de liberar las energias, las coacciona y canaliza las violencias espontáneas" (Marmande, 2009). Retenemos, también, laintención de Bataille de no perder ciertas ideas fundamentales del marxismo, tales como las contradic ciones inherentes

\footnotetext{
3Bretón estuvo ausente en dos ocasiones en las que se esperaba su presencia, el 5 y el 21 de enero de 1936. Suyra se pregunta si se debe al rechazo de Bretón hacia un proyecto que incialmente apoyó o si fue Bataille quien lo excluyó. En efecto, Bretón cometió para el autor dos errores: no destmintió a un periodista afin al fascismo, Georges Bond, quien atribuyó exclusivamente a Bretón la formación de ContreAttaque. Segundo error: Bretón concende una entrevista a un periodico llamado Le figaro que se sospechaba bajo el mando del coronel de La Rocque.Bataille, por su parte, hizo uso de la misma libertad para escribir una octavilla titulada Travellieurs vous êtes trahis! redacada solo por él pero con la firma, sin previa consulta, de, entre otros surrealistas, Bretón. En este contexto, Contre-Attaque se disuelve.
} 
al capitalismo, la lucha de clases y la necesidad de la socialzación de los medios de producción.

No olvida tampoco Marmande que para Contre-Attaque se impone la necesidad de una revolución violenta y la toma del poder por parte del pueblo armado que se anteponga al inminente ascenso, por medio de elecciones, del Frente Popular francés. Resulta importante remarcar que el autorobserva en Contre-Attaque, como Suyra,la intención del atravesamiento de los límitescuando lo define como "...la más neta experiencia (la más imposible de hacer) de la práctica social del exceso, de la puesta a prueba de las barreras y de las fronteras convenidas y del juego incesante del adentro y el afuera" (Marmande, 2009). No casualmente es a esta misma altura que Marmande introduce, a proposito de la "radicalidad de sus posiciones" (Marmande, 2014), las tensiones entre Bretón y Bataille que terminarían sucsitando el alejamiento con acusaciones de "sobrefascsimo".

Como Suyra,Marmande remarca el tratamiento en los Cahiersde temas vinculados a la sexualidad, la familia -el reemplazo de la moral capialista por otra que, desatada de toda imposción, de rienda suelta a impulsos inmediatos y sirva como base para relaciones sociales librespero también los campesinos, la patria, la autoridad y el poder. Respecto de este último punto, Marmande retoma L'autorité, les foules et les chefs, donde Bretón y Bataille se preguntan, sin contestarse, si acaso el rechazo a la autoridad puede ser el sustento de la comunidad humana. (Bataille,1970).

En esta línea, ydel repaso que el autor lleva adelante de algunos de los textos publicados por el grupo, Marmande concluye que ContreAttaque tiende a "...deshacer las normas del lenguaje político, a desafiar su ley, a riesgo de una nueva usura..."(Marmande, 2009). Se busca con ello suscitar "emociones brutas", "sobresaltos", que lleven a las masas a las calles, lugar del combate político, el terreno de los oprimidos y campo de "enfrentamiento de lenguajes" (Marmande, 2014).

\section{Richard Wolin: afinidades conceptuales, "primitivismo" y"Fascismo de izquierda".}

Richard Wolin, en su trabajo Hamado Theseduction of unreason(2006), aborda la relación entre Bataille y el fascismo en la década de 1930en un capítulo titulado LeftFascism: Georges Bataille and the German Ideology. Haremos un breve repaso por el capítulo, ya que contiene un análisis comparativo y ciertos elementos útiles para nuestro trabajo.

El autor sostiene que existe afinidad conceptual entre Bataille y los 
"jóvenes conservadores alemanes"4 - de quienes él era contemporáneo- en la medida en que en ambos casos la reflexión parte, en términos generales, de una profunda desconfianza en la democracia moderna y las ideas en que esta se sustenta. Sitúa históricamente este fenómeno: muestra cómo, ante la catástrofe de la primera guerra y el consecuente resquebrajamiento de los valores que sustentaban las democracias modernas, saltan a la luz las coincidencias ideológicas entre intelectuales de derecha e izquierda. Dicho fenómeno aparece como síntoma en el Siglo XX, y en el periodo de entreguerras en Europa con particular frecuencia, con el pasaje de inclinaciones políticas de extrema izquierda a extrema derecha siendo el mismo Mussollini el ejemplo seguramente más conocido. 5

Hecho este breve enmarque histórico, Wolin desarrolla su análisis en tres apartados. EnTransgression and "anti-ethics" hay tres puntos que merecen atención. El primero consiste en el común rechazo de la Razón por parte los jóvenes conservadores alemanes y Bataille: si los primeros opusieron a la racionalidad y el cálculo la exaltación del afecto y de las experiencias inmediatas, Bataille, por su parte, ve en la Razón uno de los operadores centrales de la sociedad homogénea, es decir, del dominio de la utilidad, la conmensurabilidad y el intercambio que "... sistemáticamente reprime las fuerzas de la vitalidad y el riesgo de donde deriva prácticamente todo lo que presenta un interés cultural"'Wolin. 2006).

El segundo punto hace referencia al rol y la valoración de la guerra: tanto en OswakdSpengler como en Bataillehay una "estética de la violencia". La guerra aparecería ocupando un rol indudablemente positivo; suscita la disolución de las individualidades, esto es, "...el principio de la subjetividad del cual el orden homogéneo de la sociedad burguesa (...) depende". (Wolin. 2006). Bataille celebra la guerra en la medida en que implica cierta materialización del "movimiento general de la vida", siendo este el gasto de energía sin sentido ni medida, aquello que se realiza, más allá de cualquier fin utilitario, como un fin en sí mismo.

Sostiene que para Bataille la guerra es una de las formas de arribo a una comunidad extática "...no ya gobernada por los prejuicios identitarios de la cultura visual - por las normas de la transparencia-, igualdad y auto-equivalencia- sino por aquellos vinculados con la auto-laceración,

4 Se hace referencia con este epíteto a un grupo de intelectuales alamanes protofascistas que tuvo influencia en la caída de la república de Weimar. Afirma el autor que dicho grupo contribuyó de forma decisiva en la "preparación espiritual" para el nacional-socialismo alemán. Dentro de este grupo se encuentran, por mencionar algunos de sus integrantes, Ernst Jünger, Arthur Moeller van der Bruck, Ludwing Klages, Ernst Niekisch, Carl Schmitt y Oswald Spengler.

5 Para ver ejemplificado este tránsito en Francia, junto un breve análisis de sus condiciones históricas. ver p. 156-158. 
la diferencia y finitud." (Wolin. 2006)

Postula el autor que esta idea -tercer punto-, ha inspiradolos escritos que sobre la noción de comunidad han desarrollado Blanchot y Nancy, quienes intentaron pensar una comunidad inmune al totalitarismo. Para el autor, ambos, al predicar los valores de lo heterogéneo y la diferencia antes que los de la sociedad homogénea y su tendencia totalizadora, propondrían un modelo de comunidad sustentado en una "estética de la transgresión como norma de la acción social". (Wolin, 2006). Dicho de otra manera, la exaltación de la transgresión en si misma implica la constitución de un puro ethos de la ruptura y lo disruptivo en el que Wolin ve un peligro por "... las implicaciones anti- morales de ese nuevo espíritu comunitario, confesadamente antiliberal" (Wolin, 2006).Nancy está lejos de proponer tal idea; al contrario, ve en la resistencia al atravesamiento del límite, que para él es el otro ser singular, una de las formas de definir la comunidad. Volveremos sobre este punto.

Antes, resulta interesante mencionar que, para Wolin, Bataille mostraría en textos de los años 30's y 40's cierto romanticismo antropológico expresado a través de la oposición entre la sociedad contemporánea y su racionalismo utilitarista y las comunidades pre modernas en tanto modelo histórico de "reencantamiento" (Wolin, 2006).Batailleafirma que la desaparición progresiva en la sociedad moderna de ciertas prácticas rituales cohesivas habría desembocado en un alto grado de inestabilidad y en una pérdida de solidaridad.

Es la lectura de Mauss la que lleva a Bataille en esta dirección, y es por ello que en el apartado Thegift of deathse detiene a analizar esa influencia. Sin detenernos en detalle en este punto, importa mencionar que Bataille se sirve del análisis maussiano de prácticas rituales no productivas, de las que se destacan el sacrificio, el potlach y el regalo. para desarrollar su teoría del gasto no utilitario. Lo hace, según Wolin, no tanto para proponer, como Mauss, cierta reincorporación de lo premoderno en la modernidad, sino más bien para rechazar la sociedad moderna en su totalidad: rechazo que, a su vez, también está presente en los jóvenes conservadores alemanes.

Aquello que falta en la sociedad moderna y que caracteriza las sociedades pre-modernas es, para Bataille, la proximidad con lo sagrado, es decir, aquello que suscita la trascendencia de la fragmentación donde toda individualidad es disuelta. Bataille propone las nociones de intimidad e inmanencia para referirse a esos estados a los que se accede a través del don y el sacrificio, pero no solo a través de esos medios. Como se mencionó, la violencia y la guerra son actos de destrucción a través de los cuales es posible franquear momentáneamente el límite entre el mundo profano y el mundo sagrado: queda atrás el mundo regido por las leyes de la reproducción y el cálculo para acceder a cierta "restauración de la "intimidad" (Wolin, 2006) 
Wolin sostiene que Bataille muestra un empleo "naive", en algunos aspectos, de los estudios etnográficos maussianos. Al descontextualizar las prácticas rituales, sus descripciones pueden volverse "superficiales", cayendo así en cierto "primitivismo" que no permite ver en ellas la reproducción de relaciones de poder(Wolin, 2006).

En LeftFascism retoma Le structure psychologique du fascismedonde Bataille presenta a la democracia parlamentaria como operador del orden homogéneo, cuyo objeto consiste en la eliminación de toda diferencia, de todo elemento heterogéneo a partir de una compleja actividad de adaptación (Bataille, 2003). Los líderes fascistas, de quienes él admiraría su soberanía y su aversión por la ley, comprenden elementos heterogéneos. Bataille establece que la acción fascista participa de las formas elevadas al tiempo que suscitan sentimientos tradicionalmente definidos como nobles, constituyendo, además, una autoridad como principio incondicional, situado por encima de todo juicio utilitario. Tal afirmación implica, siguiendo a Wolin, que "... el fascismo (...) Introduce una estética política que pone en primer plano los valores de una comunidad extática preciada por Bataille: carisma ("soberanía"), violencia, y gloria marcial" (Wolin, 2006). El fascismo despierta así fuerzas afectivas que posibilitan la renovación de lazos de solidaridad; revive aquello que la democracia moderna perdió y que caracterizaba las comunidades pre-modernas.

Para Wolin, la admiración hacia el líder fascista es una forma de emergencia de lo mítico en la modernidad, que consiste para él en una forma "imaginaria" e "irracional" de resolución de problemas sociales. (Wolin, 2006). Es cierto que el mito será abordado por Bataille de forma explícita más adelante. En L'ApprentiSorcierBataille afirmaría que el mito es el "sustrato" de la comunidad y la "expresión sensible de la existencia total". Posee, a su vez, una "dinámica violenta" cuyo objeto es "el retorno a la totalidad perdida." (Bataille, 2003).

Sin embargo, antes de tal sentencia pero después dele Critique socialeocurrió Contre-Attaque.El capítulo culmina con un análisis del grupoque representaparaWolinel tránsito de Bataille desde la izquierda a hacia la derecha en el espectro político.

Es que, como afirma Suyra, para Bataille solo las revoluciones fascistas fueron capaces de desafiar seriamente la decadencia creciente de las democracias modernas, reemplazándolas por un nuevo mito colectivo que funciona como fuente de cohesión social. Wolin postula, retomando a Lindenberg, que la revalorización de los mitos y los orígenes son elementos que cuentan con un lugar innegable en la filosofía oficial fascista (Lindenberg, 1993).

En coincidencia con Marmande y Suyra, Wolin ve en Contre-Attaque "...una fascinación sanguinaria con la violencia revolucionaria" (Wolin, 2006) que aparece de forma muy clara cuando establece la necesidad 
de crear milicias "fanáticas" y "disciplinadas" que ejerzan una "dictadura despiadada" (Bataille, 1970). Luego declara abiertamente la intención de utilizar las "armas creadas por el fascismo" que, al hacer uso de las "aspiraciones fundamentales del humano", moviliza "la exaltación afectiva y el fanatismo" (Bataille, 1970). El autor denomina "fascismo de izquierda" al lugar ideológico ocupado por Bataille en este momento, definido como la utilización de métodos fascistas para fines políticos de izquierda (Wolin, 2006). En efecto, es esa intención uno de los motivos del alejamiento de Bretón y los surrealistas. En este sentido, si bien la orientación política del surrealismo no adolecía de apelaciones a la violencia, Wolin sostiene que"...habían limites más allá de los cuales él se negaba a seguir en la fascinación de Bataille con la transgresión política" (Wolin, 2006). Cabe destacar que se hace presente, una vez más, la noción de límite.

Hay diversos elementos en el trabajo de Richard Wolin que resultan útiles para abordar los textos publicados por Contre-Attaque. En primer lugar, despliega de forma clara los paralelos conceptuales entre intelectuales alemanes declaradamente de derecha y contemporáneos a él en la década de 1930. Por otra parte, es importante resaltar cómo da cuenta de la relación y de qué lectura existe en Bataille de las sociedades llamadas primitivas: la valoración de la prácticas rituales y los mitos. Sin embargo, entendemos que, si bien pone de relieve la existencia en Bataille de cierta fascinación por el fascismo, definirlo por ello simplemente como intelectual de derecha o como "fascista de izquierda" reduce la complejidad del pensamiento político de Bataille.Con el objetivo de ampliar la reflexión en torno a esepensamiento, se retomarán en adelante algunas de las ideas presentadas por el filósofo Jean Luc Nancy respecto de la noción de comunidad.

\section{Jean Luc Nancy y la comunidad posible: la noche de la inmanencia}

La comunidad inoperante(2003), de Jean-Luc Nancy,está atravesado por la pregunta por el ser de la comunidad, su ontología. Escentral no perder de vista que este texto fue escrito cuando Nancy culminaba un curso sobre Bataille, de quien intentaba extraer alguna alternativa tanto al comunismo y al fascismo como al individualismo demócrata y republicano.

Más allá del éxito o no de tal empresab, es importante aquíseñalar que

'Tanto en La comunidad enfrentada como en La comunidad revocada Nancy reconoce no haber encontrado en esos textos de Bataille lo que buscaba: "una política inédita"(Nancy, 2002,p.22). De hecho, en La comunidad revocada Nancy concide en la critica que Blanchot le pripiciara por el hecho de querer encontrar en Bataille algo que no podia dar. No es el tema del presente trabajo; basta con mencionar que opondria en esos textos la comunidad de los amantes, sin tinte politico 
La comunidad inoperantetuvo como referencia textos deBataille posteriores a la Segunda Guerra, esto es, escritos que excluyen su producción en los años 30', momento deContre-Attaque y Acéphapleporque vio allí "...que entonces (Bataille) había experimentado el límite de una exigencia de comunión social"(Nancy, 20016). Esa desatención nada tuvo de casual, sino que respondió a un fracaso que fue reconocido por el mismo Bataille y que compuso dos aspectos: por un lado, fracaso "de hacer compartir sus puntos de vista" $y$, por otro, de "distinguirlos de puntos de vista fascistizantes." (Nancy, 2016). Ambos síntomas de una aporía todavíaactual para Nancy,que es la de la inexistencia de una alternativa seria al capitalismo. Remarca en este sentido, como Suyra y sobre todo Wolin, que en esos años aparece en Bataille, además de un intento de quebrantar el enfriamiento que en la rebelión había suscitado el Estado bolchevique, una fascinación por el fascismo, al que vio como fuente de cierta energía pülsional y extática. Pero agrega que creyó ver allí, motivado por la nostalgia de una "imagen fusional" (Nancy, 2016), la realización de una comunidad perdida.Como veremos, sea reprimida 0 no $^{7}$, lo cierto es quedicha nostalgia aparecerá con una forma determinada en Contre-Attaque.

En efecto,no es casual tampoco el punto de partida de su texto. Esel rechazo de aquella concepción que define la comunidad comoautoproduccióno producción de un sujeto trascendente, de donde resultaría que toda posible existencia singular es obra misma de la comunidad. Hablamos, en palabras del autor, del "rechazo a disponer la comunidad tanto según su propia existencia como según un sujeto que trasciende las existencias singulares y que, así, las asumiría en tanto que la obra misma del ser común (comunidad de un pueblo comprendido él mismo entidad espiritual o natural, así como comunismo entendido como fuerza de auto-producción colectiva)" (Nancy, 2003).

Ese punto de partida se monta sobre una crítica al comunismo en tanto palabra que "emblematiza el deseo de un lugar de la comunidad encontrado o reencontrado"(Nancy, 2003). De la base del ideal comunista, que consiste en definir a los hombres como productores de su propia esencia a través del trabajo, produciéndolacomo comunidad, resulta para el autor la idea de una posible comunidad absoluta, es decir, una totalidad auto-producida, cerrada, sin fisuras.

La igualdad, autoproclamado fundamento del comunismo, supone el principio de una humanidad como realización de su propia obra que, lo dice Blanchot sin titubeos en La comunidad inconfesable, "Es el origen aparentemente sano del totalitarismo más malsano" (Blanchot,

alguno, a la de adquisición, el Estado. Habrá una separación entre lo político y el estaren-común

7Blanchot en La comunidad inconfesable sostiene que la nostalgia que le suscitara el conocimiento de modos de ser comunitarios llamados primitivos, a través de la lectura de ciertos trabajos de sociología, seria "rápidamente reprimida". (Blanchot, 2003) 
2016).Totalitarismo porque esa igualdad, Ilevándola hasta las últimas consecuencias, devendría en la anulación de toda existencia singular. En otras palabras, en la medida en que el uno es totalmente igual a otro, no hay diferencia entre ambas existencias. Ahora bien, para Nancy, la mayoría de los que él llama "comunismos de oposición" (Nancy, 2003) y de los modelos de izquierda que se oponen al "comunismo real"están sustentados en ese ideal comunista cuya realización entonces no es otra cosa que totalitarismo.

La metafísica del sujeto es la del ser como absoluto en general que se define por su clausura, su separación y por su "sin relación" (Nancy, 2003), y puede - presentarse como Idea, Historia, Individuo etc. Su lógica consiste en encerrar la separación, dado que, si solo hubiese una separación de algo, esta no podría ser absoluta en la medida en que sería relativa a aquello de lo cual se separa. Dicho de otra manera,"...la separación misma debe ser encerrada, la clausura no solo debe clausurarse en un territorio (quedando no obstante expuesta, por su borde externo, al otro territorio, con el cual de ese modo se comunica), sino sobre la clausura misma, para realizar la absolutez de la separación" (Nancy, 2003). La lógica de lo absoluto es entonces la de una realización imposible porque siempre tendrá relación 0 , en términos de Nancy, "lo pone en relación" con un exterior para su constitución, lo que es lo mismo que decir que el "sin relación" es imposible. Sostiene Nancy que la comunidad -"La relación, (la comunidad)" (Nancy, 2003)"merma" el sujeto-absoluto de la metafísica porque "...deshace en su principio la autarquía de la inmanencia absoluta" (Nancy, 2003)

Retomando a Bataille, explica que hay una desgarradura entre, por un lado, la totalidad de las cosas y, por otro, el ser en nombre de o, mejor dicho, en relación al cual estas cosas son: "Esta desgarradura (...) define una relación del absoluto, impone al absoluto una relación con su propio ser (...). Así, es el ser "mismo" el que llega a definirse como relación, como no-absolutez, y si se quiere como comunidad" (Nancy, 2003) Hay, otra vez, una totalidad que el ser no puede ser, sino en relación al cual es.

Para Nancy, hasta ese momento (1983) la comunidad se pensó como perdida. Debe ser reencontrada o reconstituida ysiempre se entiende como una totalidad absoluta y autosuficiente. No siendo solo la de un justo reparto de tareas y bienes, equilibrio de fuerzas y autoridades; tampoco solo la de una comunicación íntima de sus miembros, es además "...comunión orgánica de sí misma con su propia esencia" (Nancy, 2003). Cada miembro es depositario de una identidad que es la del cuerpo de la comunidad. Para ser más precisos, es a través de la identificación con ese cuerpo que emerge aquí el miembro de la comunidad en cuanto tal.

Ahora bien, la recuperación de la inmanencia común es imposible porque la comunidad así pensada no existió. No hay comunidad 
perdida sino que, como primera definición, tal "pérdida" es constitutiva de la comunidad; a la inversa, si la inmanencia existiera, la suprimiría, siendo la muerte su verdad. En la muerte no habría otra cosa que "la continua identidad de los átomos" (Nancy, 2003), es decir, una suerte de "mismidad" por supresión de toda diferencia. Es por ello que la verdad detoda empresa política o colectiva habitada por un deseo de inmanencia absoluta, de fusión, es la verdad de la muerte, de donde se desprende que una comunidad de la inmanencia humana es entonces una comunidad de la muerte. Ese deseo es, a su vez, la base de la nostalgia por la comunidad perdida.

Pero a la imposible comunidad de la inmanencia Nancy opone la comunidad como asunción de esa imposibilidad. Esta está entonces para asumirse como la imposibilidad del advenimiento de algún tipo de sujeto colectivo, fusión colectiva o ser comunitario. Parecería, entonces, que está en lo cierto Wolin cuando advierte sobre el peligro de las derivas políticas de Bataille y su relación con la declarada exaltación de la sociedades llamadas primitivas. Sin embargo, Nancy, como puede observarse, propone otro tipo de explicación. Es Bataille tomado por la nostalgia de un "ser comulgante" quien define a las sociedades arcaicas, entre otras, como el lugar donde la comunidad tuvo lugar.

De las reflexiones en torno al fracaso de los proyectos comunitarios, Bataille extrae la idea que define la soberanía -verdad de la "experiencia interior"- como el abandono ala exposicióna un exceso que es una exterioridad irrecuperable. Con ese afuera inasible hay sin embargo una relación esencial cuyo "espacio" o "ritmo", para Nancy, es solo provisto por la comunidad. Ya no, entonces,la reconstrucción de una obra, sino más bien "...el espacio mismo, y el espaciamiento de la experiencia del afuera, del fuera de sí." (Nancy, 2003, p. 44). Experiencia no del reencuentro fusional, imposible y a fin de cuentas tampoco deseable, sino conciencia de una irremediable separación que solo existe como comunicación en y a través la comunidad.

Tal conciencia aparece bajo la forma del éxtasis: "la comunidad es la conciencia extática de la noche de la inmanencia, por cuanto esa conciencia es la interrupción de la conciencia de sí" (Nancy, 2003, p.46).El éxtasis, es decir, la respuesta a la imposibilidad de la inmanencia, y la comunidad son recíprocos en dos sentidos. ${ }^{8}$ Lo son porque no existe el uno sin el otro $y$, al mismo tiempo, se limitan, esto es, "... una suspensión de la inmanencia a la cual, con todo, la conexión entre ambos implica.", de lo que resulta la resistencia a la fusión o la obra mortal, que es "...el hecho del estar-en-común en cuanto tal..."(Nancy, 2003).

${ }^{8}$ Como ya se sugirió antes, Bataille, muestra Nancy, mantuvo separados estos dos polos, incluso en los textos de él que lo inspiran, situando del lado del éxtasis al fascismo y la comunidad de los amantes, y de lado del comunidad al comunismo. 
La comunidad es pensada por el autor como un reparto que no es otra cosa que el espaciamiento de seres singulares, siendo la comunidad misma, por ende, la exposición de finitudes.Más precisamente, la singularidad, la finitud, emerge en la experiencia del límite que es para mí otro ser singular, por lo que no existe singularidad no compartida ni no expuesta: aparecen en ese mismo instante, no antes.Así, la comunidad es siempre la de los seres finitos. En otras palabras, es una participación necesariamente simultánea que hace existir cuando en la exposición del límite crea "la proximidad con el alejamiento" (Nancy, 2007). La comunidad es la forma de existencia primigenia no en cuanto primera, sino como "socialidad ontológica" (Nancy, 2003) lógicamente anterior a toda forma singular o plural, a todo mundo.

La comunícación aquí esla compartición de la finitud, otra forma de decir que es la compartición de la imposibilidad de la comunidad en tanto unión.Nancy sostiene que lo que se comunica es la pasión que aparece desencadenada en la singularidad ante la existencia de otra que, a través de la revelación del reparto, padece en su alteridad. Los seres son semejantes, entonces, por lo mismo que los separa: la finitud, siendo la comunidad es su "régimen ontológico".

La comunidad, entonces, no puede ser nunca una obra, sino solo experiencia de la finitud 0 , como diría más adelante, el "coestar" donde el "con" "...designa el espacio sin omnipotencia y sin omnipresencia" (Nancy, 2007). Dicho de otra manera, hay inacabamiento puesto que solo hay comunicación de la finitud, solo "...la actividad del reparto, la dinámica (...) del tránsito ininterrumpido por las rupturas singulares (...) una actividad inoperante." (Nancy, 2003).

En este marco, la "masa fascista" aparece como aquello que tiende a consumar la obra de muerte, a "aniquilar la comunidad en el delirio de una comunión encarnada". (Nancy, 2003).La comunidad obrada es la "condena a muerte de la sociedad" en todos los sentidos, incluido el de la institución de la pena de muerte. (Nancy, 2007)

Pero la comunidad es, en cierto sentido, la resistencia a la inmanencia o, más precisamente, al deseo de inmanencia movilizado por la angustia del estar-en-común. Si en la comunidad de los amantes el tocar implica el arribo al límite, es decir, a aquel estado donde la imposible inmanencia aparece como más próxima, no se la debe confundir, llevándola a los "conciudadanos", con "el delirio de una masa fanatizada" (Nancy, 2003). De allí se desprende que hay traspaso del límite, en la medida que lo hace desaparecer, solo puede tener la forma de la aniquilación del otro. Esto es para Nancy la violencia. 


\section{Contre-Attaque}

Si existe una constante en los diversos textos publicados por la agrupación, es la apelación al uso de la violencia. Es por ello que no hace falta ir muy lejos:basta leer la primera octavilla: "Violentamente hostiles a toda tendencia, sea cual sea su forma, que capta la Revolución a favor de ideas de nación o de patria, nos dirigimos a todos aquellos que, por todos los medios y sin reservas, están decididos a derribar la autoridad capitalista y sus autoridades políticas" (Bataille, 1970).Inmediatamente después, se considera"eliminado" aaquel que no olvide la "fraseología política", a aquel que no pase a ser "realista";"lama finalmente a la "liquidación de las autocracias". (Bataille, 1970).

Además del expíicito anticapitalismo y antinacionalismo, parece claro que si la base del ideal comunista denunciada por Nancy en toda oposición de izquierda aparece de alguna forma, lo hace en ContreAttaquebajo la forma no tanto de una doctrina elaborada, sino más bien mediante la apelacion a la violencia. Para ser mas precisos, pareciera entonces cierto que, al no haber un desarrollo filosófico y político como en trabajos tanto posteriores como procedentes; al no haberreflexiones como las que pueden leerse desplegadas en los años de Acéphale y el Collège de Sociologieo, antes, en Le structure psychologique du fascismey La notion de dépense-para citar solo algunos-, aquella base del ideal comunista denunciada por Nancy se expresa de esa forma.En efecto, Contre-Attaquellama a la "constitución de una doctrinaresultante de experiencias inmediatas" para luego volver a exigir la toma del poder a través de una "violencia imperativa" (Bataille, 1970).

Si llama la atención tal insistencia en el uso de la violencia tan solo en los primeros cuatro párrafos, es aún más llamativa la exigencia de una "intratable dictadura de la gente armada" y la "creación orgánica de una basta composición de fuerzas, disciplinadas, fanáticas, capaces de ejercer llegado el día una autoridad implacable (...) Ella debe dirigirse a todos aquellos que no se sientan hechos para ser conducidos por los sirvientes y los esclavos - que exigen vivir en conformidad con la violencia inmediata del ser humano" (Bataille, 1970). Entonces no simplemente se presenta la violencia como un medio, sino también como un elemento inherente al ser humano. Es decir, es tanto el medio de eliminación de aquel que se resista a la revolución como un carácter en cuya conformidad todo revolucionario demanda vivir.

En la segunda octavilla, titulada Positions de l'union sur des points essentiels, salta a la vista aquello que el propio Nancy se encarga de dejar en claro en La comunidad enfrentada (2007), esto es, la institución de la pena de muerte como la condena a muerte de la sociedad. Leemos que Contre-Attaque diagnostica la existencia de una organización social que coarta las "posibilidades de desarrollo humano" 
y que por ello, sostienen,"no titubeamos en afirmar la pena de muerte para aquellos que asumen ligeramente la responsabilidad de tal crimen".(Bataille, 1970). Es posible, entonces, afirmar que aquello que el filósofo francés define como el deseo de una obra de muerte que está en la base de la nostalgia por la comunidad perdída -y/o venidera- se expresa en este momento sobre todomediante una exaltación de la violencia.

En este sentido, si ya en el primer párrafo de la primera octavilla rechazan violentamente a todo aquel que pretenda conducir la revolución a favor de las ideas de patria o nación, en la segunda el razonamiento es el mismo: "Pero nosotros afirmamos que la exaltación afectiva que debe estar al servicio del interés universal de los hombres debe ser más grande y destructiva, de una magnitud distina de la de los nacionalistas al servicio de la conservación social de los intereses egoistas de las patrias. Sin reserva alguna, la Revolución debe ser totalmente agresiva..."(Bataille, 1970).Luego, en el parrafo siguiente, leemos nuevamente que la Revolución no debe ser desviada hacia un nacionalismo oprimido; al contrario, es gracias a su "significación humana profunda" y "universal" que esta "salvará a los hombres" (Bataille, 1970)..

Al leer los Cahiers tampoco hace falta ir muy lejos para encontrar una vez másun antinacionalismo violento. En Mort aux esclaves, escrito en conjunto por Bataille y Bretón, sostienen que la tierra debe ser "librada" de "Los gobernantes y sus patrones -que- son los esclavos al servicio de la patria y el capitalismo", y proponen para ello "el principio de una renovación de la violencia revolucionaria"(Bataille, 1970). En Front populaire dans la rue Bataille es contundente cuando afirma que "El régimen democrático no puede ser salvado". El Frente Popular no cuenta con la capacidad de dirigirse hacia la toma del poder revolucionario; debe ser convertido en un"Frente Popular de Combate" que tome el poder de la calle. Las circunstancias empujan para Bataille a la "fusión" de las fuerzas revolucionarias en un "crisol incandescente" (Bataille, 1970).

Un violento rechazo al régimen democrático y una frase que no deja de llamar la atención. "Fusión en uncrisol incandescente" evoca aquello que, como vimos, Nancy llama a resistir en tanto que convoca siempre a la obra de muerte;no puede ser otra cosa aquí que indiferenciación a la que solo es posible acceder mediante un atravesamiento del límite. Los tres autores retomados en la segunda parte del presente escritointuyeron de distinta forma pero acertadamenteque una de las caracteristicas distintivas de Contre-Attaque se vincula con la intención de atravesar límites. Nancy parte deaquella exigencia de comunión social que Bataille llevara a su punto máximo en la década de 1930 para proponer en su lugar la idea de comunidad basada en la resistencia a esa demanda. Si solo hay reparto de singularidades que 
comparten sus límites, el llamado al atravesamiento de ese límite que es el otro ser finitoes la violencia y esta se igualaaquí al deseo de una obra de muerte. A esta altura, parece claro por qué, más allá de la importancia del trabajo de Richard Wolin, es necesario destacar que se mostró impreciso al afirmar que Nancy propone un ethos de la transgresión.

La patrie ou la terre sostiene que así como un nazi puede amar a su patria y morir por ella, ellos, el movimiento Contre-Attaque, puede amar hasta el fanatismo no ta comunidad francesa, sino la "comunidad humana". Hace falta, continúan, la emergencia de una "conciencia universal que ligue la libertad moral y la solidaridad de aquellos que no poseen nada." (Bataille, 1970). Se observa allí, una vez más, aquello que Wolin define como "fascismo de izquierda", es decir, la utilización de medios fascistas para objetivos políticos de izquierda.

Ahora bien, por un lado, Wolin mostró cómo de la lectura de los trabajos que Mauss relizara sobre las comunidades premodernas Bataille extrae la certeza de que allí hay una fuente de fuerza afectiva y cohesión social. Esta forma de expresión de la nostalgia por la comunidad perdida se observa, para traer un ejemplo claro, en el pasaje antes citado de L'ApprentiSorcier.La apelación al mito, sobre todo por cómo allí lo define Bataille, no es tanto una forma de resolución imaginaria de los problemas sociales, como sotiene Wolin, sino una totalidad perdida que es necesario recuperar. El retorno "a la vieja casa humana", el mito, "que expresa la totalidad de la existencia", puede dejar de ser un ahelo "alimentado por descripciones históricas" (Bataille, 2003).

Por otra parte, vimos que en Contre-Attaqueesa nostalgia se muestra de otra forma. Más directamente ligado a lo político y apareciendo sobre todo mediante un llamado a la violencia, Contre-Attaque puede leerse como llamado a la ejecución de una obra de muerte. Es cierto, comosostiene Wolin, que finalmente la utilización de las herramientas provistas por el fascismo se confunde con un apego a la causa fascista (Wolin, 2006), pero Nancy nos permitió observar allí algo más. Sobre todo del llamado al uso de la violencia, pero también del llamado a la liberación de los instintos y la vivencia de experiencias inmediatas, a la exaltación y al fanatismo, se desprende un mismo deseo. En esto o, mejor, por esto, apoyados además, por un lado, en las coincidencias más estrictamente ideologicas que nos mostró Wolin como así también por cierta fascinación de Bataille por determinadas prácticas rituales de las sociedades premodernas en las que finalmente vio la evidencia histórica de una totalidad perdida, podemos afirmar que Bataille, viendo en el fascismo una fuente de energía cohesiva, fue ciertamente afin al fascismo. Tentiendo en cuenta todos estos elementos no fue suficiente, entiendo, intentar distinguir el fascismo, supuesto desvío nacionalista de la revolución. En defintiva es en ambos casos la invocación al advenimiento de una comunidad absoluta, imposible 
para los seres finitos.

Observamos a lo largo de la lectura de las publicaciones de ContreAttaquelos elementos con los que las diversas interpretaciones caracterizaron sus ideas: un llamado a la acción violenta, a una dictadura del pueblo armado que debe llevar adelante una revolución en favor de los intereses universales del hombre. Es el llamado de un grupo de intelectuales que se declara anticapitalista, antinacionalista, antifascista, pero que sin embargo se muestra fascinado por la exaltación y el fanatismo que suscita el fascismo.

Concluimos de lo expuesto que el llamado a la acción violenta, a la eliminación del otro ser irreductiblemente singular es la forma que en Contre-Attaque toma la exigencia comunitaria de la que el mismo Bataille se arrpentirá.

\section{Palabras finales:}

Pareciera que es allí donde Blanchot anuncia y Nancy oye su fracaso dondepuede encontrarse también el éxito de su empresa: allí dondeNancy busca algo que no puede encontrar, una política inédita en Bataille, formula, conBatailley más allá de él(Nancy, 2002), una crítica potente y simultánea tanto a las bases ideológicas del comunismo y del fascismo, como de la democracia republicana moderna. Allí, finalmente, donde insiste la comunidad como obra, Nancy sitúa su "desobra": la exigencia no ya de la restitución de alguna inmenencia absoluta, sino del rehúso a ella.

Es gracias a ello que es posible -aunque sea de forma siempre provisoria- darle un lugar más preciso al grupo Contre-Attaque dentro de la historia del Georges Bataille político. Dado el carácter provisorio de las reflexiones aquí planteadas, resta elaborar, en adelante, un análisis más acabado y completo de las publicaciones del grupo Contre-Attaque tanto como una puesta en relación con los textos precedentes e inmediatamente posteriores. 


\section{Bibliografía:}

Bataille, G. (1970). (OEuvres completes I, París, Gallimard, pp. 374-432.

Bataille, G. (2003).La conjuración sagrada, Buenos Aires, Adriana hidaalgo.

Blanchot, M. (2016).La comunidad inconfesable, Arena Libros, Cap 1, pp. 11-49

Coloquio dirigido por Phillipe Sollers y publicado como Bataille. España, Madrágora, 1976, pp.135-170.

Marmmande, F. (2009), Georges Bataille, político, Buenos Aires, Del Signo, pp 62-70

Nancy, J, (2007).La comunidad enfrentada, Buenos Aires, La Cebra.

Nancy, J. (2016).La comunidad revocada, Buenos Aires, Ed. Mardulce.

Nancy, J. (2003).La comunidad inoperante, Madrid, Editora Nacional, pp. $19-80$

Alonso Mislata, S.(2014).Georges Bataille y la ausencia del mito, UNIVERSITAT DE VALĖNCIA Facultad de Filosofía y Ciencias de la Educación Departamento de Filosofía Área de Estética y Teoría de las Arte. Descargado http://roderic.uv.es/bitstream/handle/10550/43890/150515.pdf?sequenc $\mathrm{e}=1$

Michel Suyra, M. (2014).Georges Bataillela muerte obra, Madrid, Arena, pp. 259-289

Wolin, R. (2006), The seduction of unresaon. The intelectual romance with fascism from Nietzsche to postmoderism Princeton, Princeton University Press, pp. 153-186 